\title{
Le Morte de Perlesvaux: el Perceval le Gallois d'Éric Rohmer i l'Excalibur de John Boorman Pere Giner-Mira
}

No totes les pellícules que prenen un llibre com a punt de partida hi estableixen la mateixa relació i, com diu Brian McFarlane, no té sentit considerar tots els casos sota una mateixa etiqueta d'adaptació, sinó que convé tenir en compte la intenció del creador cinematogràfic en elaborar la seva obra.1 Des d'aquest punt de vista, les maneres de fer una pellícula a partir d'un llibre són bàsicament dues. Així ho distingeixen Joan Tasker Grimbert i Norris J. Lacy per al panorama francès de les fonts en les obres artúriques, però ho podem generalitzar: l'apropiació d'elements artúrics per elaborar un missatge filosòfic o polític personal, i la creació d'una nova narració a partir de tota o part de la història artúrica.

Grimbert \& Lacy (2009: 548) proposen dues grans categories respecte a la reelaboració de fonts artúriques. El primer tipus és el de les «works that, instead of renarrating the Arthurian legend or part of it, simply appropriate an Arthurian character or theme for use in the elaboration of a personal, philosophical or political statement»; el segon, «comprises texts that re-

1 Diu McFarlane (1996: 22) que «it does seem important in evaluating the film version of a novel to try to assess the kind of adaptation the film aims to be. Such an assessment would at least preclude the critical reflex that takes a film to task for not being something it does not aim to be». tell part or all of the Arthurian story as it became known to French authors»). En canvi, McFarlane (1996: 10-11) recull inventaris que distingeixen «three possible categories [d'adaptacions ...]: first, 'fidelity to the main thrust of the narrative'; second, the approach which 'retains the core of the structure of the narrative while significantly reinterpreting or, in some cases, deconstructing the source text'; and, third, regarding 'the source merely as raw material, as simply the occasion for an original work'».

Prendrem com a exemples d'aquestes dues operacions Excalibur (1981) de John Boorman i Perceval le Gallois (1978) d'Éric Rohmer. Rohmer vol que la seva pellícula segueixi sent i funcionant en la mesura del possible tal com és i funciona el text medieval de què parteix, el Perceval ou le Conte du Graal de Chrétien de Troyes, roman de finals del segle $\mathrm{XII}^{2}{ }^{2}$ i per això els crèdits inicials de la pellícula anoten una autoria compartida («Perceval le Gallois, texte de Chrétien de Troyes, traduit et mis en scène par Éric Rohmer», min. ০০:O০:18). Els crèdits finals d'Excalibur assenyalen com a font l'obra de Thomas Malory Le Morte Darthur, sembla que acabada el 1469 a la presó de Newgate, a Londres;3 però ho fan admetent que

2 Sobre Chrétien de Troyes, vegeu el pròleg de Riquer (1995) i també Putter (2009).

3 Segons les cronologies inicials de Shepherd (2004: 
la pellícula no és completament fidel al llibre. ${ }^{4}$ La bibliografia ha assenyalat moltes altres fonts d'Excalibur, entre les quals destaquen els Idylls of the King del poeta Alfred Tennyson, el text teòric From Ritual to Romance de Jessie Weston, o el mateix Conte du Graal de Chrétien de Troyes. Crec, però, que la font principal de matèria artúrica que fa servir Boorman és el coneixement que ell sap que en té el seu públic.

\section{Fonts literàries d'Excalibur}

Per a l'ús de Tennyson, Whitaker (2002: 44-45). Sobre la influència de Weston, Marino (2004: 2). Boorman diu haver llegit el text de Weston a Kennedy (1981). També The Hero With a Thousand Faces de Joseph Campbell intervé en Excalibur; més, em sembla, del que assenyala Davidson (2007: 73). Marino (2004: 2) també afegeix com a font de Boorman la novella The Once and Future King de T.H. White. Hoyle (2012: 120) descriu el primer esborrany conservat del guió d'Excalibur que, diu, deriva de Chrétien de Troyes. Queden vestigis del Conte a Excalibur: el primer Perceval, innocent, no es creu que el món sigui prou gran per poder recórrer-lo enllà durant vint dies (Boorman 1981, min. 01:02:46); fascinat pel cavaller Lancelot, vol ser cavaller ell també (min. 01:02:23); Lancelot li diu que se'n torni amb la seva mare (min. 01:01:33); i davant del Graal que sagna no sabrà dir el que ha de dir, cosa que el farà errar pel món més del compte (min. 01:40:02).

Tant el Perceval de Chrétien de Troyes com Le Morte Darthur de Malory són obres clau entre les narracions sobre el rei Artur i els seus cavallers, una tradició desenvolupada a partir de la Historia Regum Britanniae de Jofre de Monmouth i de la traducció en francès de Wace, el Roman de Brut. Malory vol abastar tot aquest univers: com recull Brian Hoyle (2012: 130-131) ha estat comparat a

XXvI). Vegeu també Marino (2004: 22-27) i Windeatt (2009).

4 Diuen els crèdits: «Adapted from Malory's Le Morte Darthur by Rospo Pallenberg» (Boorman 1981, min. 02:12:05ss). Hi ha un canvi implícit en adapted («adapt. [v. with'm obj.] make (something) suitable for a new use or purpose; modify», ODE, s.v. adapt). Davidson (2007: 68) qualifica l'actitud de Boorman vers Malory de «dismissive» i de «condescending».
Homer i Virgili, i la seva obra a la llíada, mentre que Barry Windeatt (2009: 84) parla de Le Morte Darthur amb el terme Arturíada. Chrétien, en canvi, com en totes les seves obres conservades, se centra en un dels personatges que formen part del cicle, 5 Perceval, tot i que el Conte du Graal també narra aventures de Galvany. Diu Martí de Riquer (1995: 23-24): «el conjunt de versos que avui coneixem amb el títol del Conte del graal reuneix, arbitràriament, dues novelles distintes del gran escriptor, totes dues inacabades, que podríem anomenar el *Perceval i el *Galvany.» Inacabades perquè «la mort sorprengué Chrétien» mentre les escrivia. Sempre segons Riquer, aquestes dues novelles haurien estat intercalades «impròpiament» per «la persona que prengué càrrec dels esborranys del difunt Chrétien per tal de donar-los una forma llibresca definitiva». Ni Ad Putter (2009) ni Rupert T. Pickens (2005: 171-175) consideren que el Conte du Graal resulti de combinar inadequadament dues novelles, tot i que Pickens assenyala que el Conte és l'única novella de Chrétien en què hi ha un «segon protagonista» amb possibilitats de destronar el primer, i ho comptabilitza en percentatges que es mouen a l'entorn d'una distribució de 50\% del llibre dedicat a Perceval i 50\% per Galvany. Rohmer pren el text com una sola narració, si bé se centra en Perceval.

\section{Text $\mathrm{i}$ imatge}

Rohmer i Boorman tenen, doncs, intencions diferents i duen a terme operacions diferents en realitzar, respectivament, Perceval le Gallois sobre el Conte du Graal i Excalibur tenint en compte Le Morte Darthur. Boorman vol fer una pellícula convencional per transmetre un missatge que és propi seu. Quant al llenguatge cinematogràfic,

5 Segons Douglas Kelly (2009: 145), Chrétien presenta al seu públic una disjuntiva, un jeu parti, en cada novella: «The typical jeu parti stages a debate between two speakers who argue for opposing points of view. [...] These controversial positions show how Chrétien's romances pose problems to which the answers they provide, far from being definitive, provoke debate among narrative characters whilst challenging audiences and flirting with irony that lightens the earnestness of the debate». 
no es planteja apartar-se dels patrons fílmics associats amb el que Noël Burch (2007) anomena mode de representació institucional (MRI): estructuralment, segueix l'estàndard de guió en tres actes, amb la tríada protagonista-objectiu-obstacles i respectant el principi d'unitat d'acció. Quant al contingut, recorre a Malory veient-lo com a Arturíada, un panorama total del corpus artúric en què pot trobar completa aquesta mitologia. Perquè és com a mitologia que Boorman entén la matèria artúrica; ho va explicar a Harlan Kennedy mentre rodava la pellícula ( «l think of the story $[\ldots]$ as a myth. The film has to do with mythical truth» ('Entenc aquesta història [...] com un mite. La pellícula té a veure amb una veritat mítica'), ${ }^{6}$ i ho va reiterar amb Excalibur ja acabada («That was my aim in Excalibur, to touch the mythic, archetypal sources that begat us» 'Aquest era el meu objectiu a Excalibur, tocar les fonts mítiques, arquetípiques que ens van originar', Boorman 1986: 41). Aquesta voluntat mitològica de partida queda confirmada per les vicissituds del projecte: quan la United Artists va rebutjar la idea original de Boorman, centrada en Merlí, i li va oferir com a contraproposta una adaptació d'El Senyor dels Anells, igualment mite, ell va passar sis mesos elaborant-ne un guió, que va haver d'abandonar per dificultats de producció i problemes de drets; llavors va tornar a la idea artúrica inicial?

A aquesta voluntat mitològica Boorman afegeix una allegoria de tipus ideològic, per la qual podem interpretar cadascun dels personatges principals com la personificació d'un valor o entitat abstracta. Aquests valors, organitzats al voltant d'Artur, permeten a Boorman de transmetre una seva concepció del bon govern oposat al mal govern. La seva intenció, doncs, és presentar una mitologia i una ideologia en forma d'imatge.

6 Kennedy (1981). La cursiva és seva.

7 Ho explica a Boorman (1986: 20-21), tot confirmant que també entén l'obra de Tolkien com a mite. Vegeu també Lemons (2001).
Quant a la mitologia, per exemple, no vol explicar a l'espectador que Artur és l'únic que pot arrencar Excalibur de la roca, sinó que vol que ho vegi. I quant a la ideologia, una allegoria és essencialment una posada en escena, i l'escènic és visible, és també imatge. Per tant, Boorman ho subordina tot — també el text de Malory — a la imatge. ${ }^{8}$

En canvi, Rohmer vol fer intelligible al públic de la seva època — que també és la nostrauna obra que, pel fet de pertànyer a un altre període i doncs a un altre sistema interpretatiu, és de difícil lectura avui. ${ }^{9}$ Per això en manté els mecanismes i el contingut, i per això també situa el text com a columna vertebral de la pellícula i li dóna preeminència sobre tota la resta de dispositius que articula _ i en concret sobre la imatge_- fins al punt de mantenir el vers recitat o cantat i de limitar-se a fer-ne una traducció. ${ }^{10}$ Xavier Kawa-Topor parla de «traduction partielle» i descriu la llengua de la pellícula com un híbrid entre el francès contemporani i l'antic.

Rohmer també manté la tesi argumental de Chrétien — que Kawa-Topor (2011: min. 01:11:53) enuncia com «L'armadura no fa el cavaller»-i es limita a arrodonir-la. El motor de la quête de Perceval és la visió d'un grup de cavallers, sobretot de les seves armes i de l'armadura i cotes de malla; aquesta visió, nova per a Perceval, el fascina: nova

8 El tràiler d'Excalibur no considera que recollir l'origen en el text de Malory -o en qualsevol altre textsigui necessari per vendre la pellícula. El tràiler de Perceval, en canvi, sí que esmenta Chrétien de Troyes. Els tràilers són sempre una bona eina per saber com entenen una pellícula els que l'han feta; al d'Excalibur una veu en off d'aire circense diu: «A world of wizards, kings, warriors, queens, swords, sorcery and desire». Vegeu aquests tràilers a les adreces especificades a la bibliografia.

9 Fins al punt de ser, malgrat la seva importància literària, desconeguda, també a França. Ho assegura Rohmer en l'entrevista inclosa al com-se-féu En répétant Perceval de Jean Douchet (1978: min. o0:48).

10 En paraules de Grimbert (2009: 554), «Rohmer [...] simply films the text» de Chrétien. 
perquè després de la mort del seu pare, que era cavaller, sa mare l'havia allunyat de la cavalleria. Aquesta fascinació porta Perceval a voler ser cavaller, que ell entén que consisteix a muntar a cavall i portar armes i armadura: per això quan en el seu primer enfrontament mati el Cavaller Vermell el primer que en voldrà serà l'armadura, i creurà que la cota de malla és una segona pell. Haurà de descobrir, a través de l'amor cortès, sobretot amb Blancaflor però també amb la Pucelle que Ké frappa, que ser cavaller també i sobretot exigeix un aprenentatge espiritual. Aquesta tesi ja és la del Conte du Graal i segueix sent la de Perceval pellícula.

En una conferència al Forum des Images, Xavier Kawa-Topor (2011: min. o0:32:55) afirmava: «On n'est pas dans un français contemporain, on est dans un français qui emprunte à la langue romane [vol dir el francès antic] mais qui n'est pas tout à fait la langue romane». Així, quan Chrétien escriu «•v• chevaliers armés | de toutes armes acesmés, | et moult grant noise démenoient» (Potvin 1977: 45), Rohmer (1978, min. 00:03:09) reescriu «cinq chevaliers armés, | de toutes armes adoubés. | Et moult grand fracas démenaient». És a dir, actualitza les formes de morfologia flexiva (démenoient esdevé démenaient) i substitueix el lèxic que ha deixat de ser comprensible (canvia noise per fracas, i acesmés per adoubés) però manté tot allò que, per bé que arcaitzant o estrany, pot ser entès, tant en el lèxic (moult no és desplaçat per très) com en la sintaxi (es queda amb l'estructura dislocada basada en la forma de participi de toutes armes adoubés).

L'escena de la Passió del Crist/Perceval és afegida per insistir en aquesta tesi. Ja al text de Chrétien es diu que, per completar el seu aprenentatge espiritual cavalleresc, «Ensi Percevaus reconnut | que Diex au venredi reciut | mort et si fu crucefiiés; | À le Pasque, acumeniiés | fu Percevaus moult dignement» ('Així Perceval va recordar que Déu el divendres va ser mort i crucificat i per Pasqua Perceval va combregar molt dignament', Potvin 1977: 263-264). És a partir d'aquests versos que Rohmer decideix desenvolupar la seva escena de la Passió," el text

11 Dic que l'escena és afegida, però no que sigui sorpre- de la qual, en llatí, segueix els evangelis de Joan i de Mateu.2 Transformant Perceval en Crist, d'una banda, la pellícula diu que l'aprenentatge de Perceval és en la pròpia carn. De l'altra, Kawa-Topor (2011, min. 01:16:12) explica que s'estableix una simetria per la qual, si bé la quête de Perceval havia començat per la seva fascinació per un cavaller —identificable amb el seu pare - que ell confonia amb Déu (Déu-Pare), la quête culmina amb Perceval perfent el seu aprenentatge de cavaller en la posició de Jesucrist (Déu-Fill).

El fragment comença amb el versicle en què Crist pregunta qui busquen («Quem quaeritis?») als romans que vénen a detenir-lo a Getsemaní: la mateixa pregunta — present en tots quatre evangelis - que fa l'àngel a la Mare de Déu quan visita el sepulcre de Crist i descobreix que ha ressuscitat, de què va derivar «the famous Quem quaeritis» que Richard B. Donovan (1958: 11) assenyala com «by far the most important [trop] for our consideration», perquè «out of this piece was to evolve the earliest recorded play of the medieval Church» ('de molt el trop més important a considerar perquè a partir d'aquesta peça va evolucionar l'obra de teatre més antiga de l'Església medieval').13 Donovan (1958: 7) considera central en aquestes obres que les escenes fossin reproduïdes «in a distinctly dramatic manner», i

nent -en el sentit de discorde-, com els sembla a Rider et al. (2002: 157): «Rohmer's departure from his model at this point is all the more surprising because of his scrupulous fidelity to Chrétien's romance up to this point». L'escena de la Passió no va en direcció contrària a la de la fidelitat escrupolosa que Rohmer manté a la resta de la pellícula, sinó que creix dels cinc versos de Chrétien que indico. Té raó Rohmer quan diu - com recullen, amb escepticisme, Rider et al. (2002: 157) - que «Je n'ai fait qu'être très fidèle à Chrétien de Troyes » (Magny 1979: 18).

12 Seguint la Vulgata, comença a Jo 18,4 i va resseguint per fragments l'evangeli de Joan fins a Jo 19,18. Llavors passa a Mt 27, de què reprodueix els versicles 39 i 40.

13 Donovan (1958: 10) defineix trop com «a verbal amplification of some passage of the liturgy, either as an introduction, an interpolation, or a conclusion, or any combination of these.» Per aclarir la definició, afegeix: «For example, the final Ite, missa est of the Mass, and its response, were frequently troped by the insertion of a phrase between the first and last words of the formula; the following variation is typical: Ite nunc in pace, spiritus sanctus super vos sit, iam missa est. I Deo semper laudes agite, in corde gloriam et gratias». 
estableix com a criteri per distingir què és drama i què no que hi hagi un actor que faci el paper d'una altra persona, és a dir, que hi hagi «impersonation» (Donovan 1958: 6). Més endavant, en el capítol dedicat a Vic i a la Seu d'Urgell, diu: «The two clerics at the altar clearly represent, or symbolize, the angels, and the other two who answer their queries are undoubtedly thought of as the "Marys") ("És clar que els dos clergues de l'altar representen, o simbolitzen, els àngels, i els altres dos que responen a les seves preguntes són sens dubte concebuts com les Maries', Donovan 1958: 77). Ens hi fixem aquí perquè Rohmer també dóna importància al mecanisme d'«impersonation», d'encarnació, a Perceval: els seus actors diuen no només les línies de diàleg del seu personatge sinó també les frases atribuïbles al narrador que parlen del personatge en

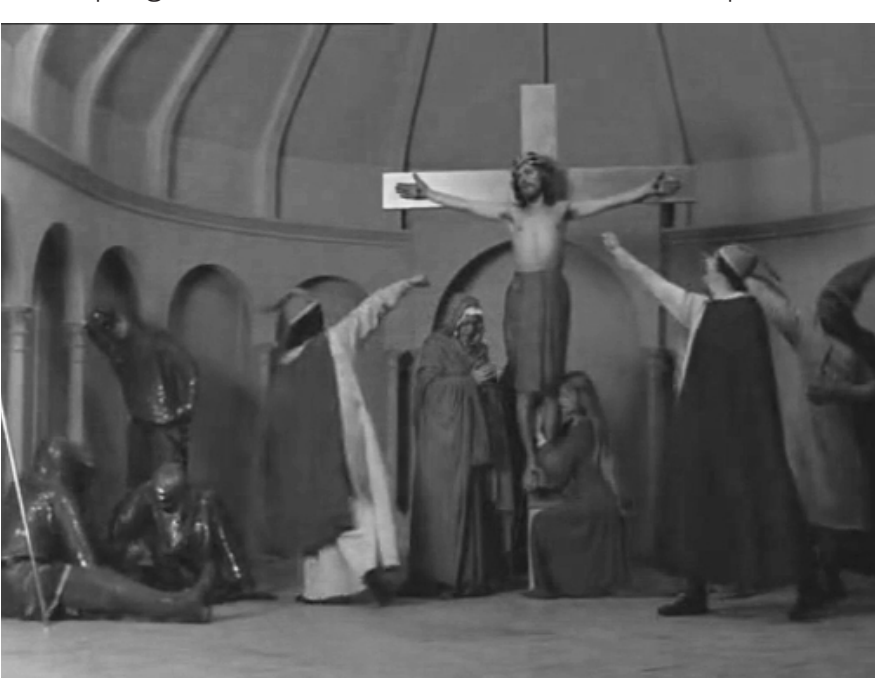

La Passió de Perceval (Rohmer 1978, min. 02:10:54). i, encara que no necessàriament relacionant el segle amb Malory, el públic actual identifica el segle xv com l'ambientació artúrica per defecte. ${ }^{15}$ Boorman, com fa Perceval al principi de la seva quête, sembla creure que l'armadura és una part del cos del cavaller, de manera que Uther porta tota l'armadura quan engendra Artur amb Igraine -i el contrast entre Uther amb armadura i Igraine completament nua no pot ser més descarat (min. oo:14:24). També en porten Artur i els seus cavallers quan el rei proclama que «la pau fa temps que regna al país» - i per tant l'armadura no és defensiva; és més aviat el vestit de mudar per anar a sopar.16 I al final de la pellícula Artur pren el pols a Lancelot per descobrir que és mort, encara que tots dos porten l'armadura posada (min. 02:06:50). No hi ha cavaller sense armadura i el cavaller que ve al cap en sentir aquest terme és el del segle $X V$ (Kawa-Topor 2011, min. 00:14:26).

natges tot sovint parlin d'ells mateixos en tercera persona, que l'espectador vegi a la vegada l'actor i el personatge durant tota la pellícula i, doncs, la «impersonation» es fa evident, queda en primer pla. Així, Rohmer, meteur en scène -i és igual aquí si de cinema o de teatre-, desenvolupa aquest episodi final metalingüístic per encaixar la pellícula de manera sòlida en la tradició de l'escenografia. ${ }^{14}$

On sí que sembla que l'armadura faci el cavaller és a Excalibur. La pellícula vesteix Artur i els seus cavallers amb armadures del segle XV. Això pot venir directament de Le Morte Darthur, en què, com és habitual en els textos medievals, el passat s'explica en termes del present, com assenyala Whitaker, però també pot ser, i penso que és més això segon, que només sigui perquè Malory constitueix «the definitive English version»

14 Vegeu també Coote (2012: 516).

\section{Simbolismes}

A més, les armadures d'Excalibur també són explotades des del departament de fotografia, fenthi reflectir una llum verda que dóna la tenor cromàtica de tota la pellí́cula. Per tractar la llum -i en concret la llum verda- de Boorman, va bé de recórrer al model de color HSB, que descompon els colors en valors sobre tres eixos, el to, la sa-

15 Whitaker (2002: 44) detalla com «references to architecture, costume, arms and armor, to the military campaigns of the Hundred Years' War and the Wars of the Roses, to commercial details, and to the use of cannon fix Arthurian society in the late Middle Ages. Lacking the concept of historical perspective, author and audience visualized the past in contemporary terms».

16 Boorman (1981, min. 01:06:54). Hoyle (2012: 123) també se n'adona. 
turació i la claredat; el to verd serveix per «emphasize the moss and the leaves» 'posar èmfasi en la molsa i les fulles', segons explica Boorman a Kennedy (1981). Però si només fos per això no caldria aquesta llum, perquè la molsa i les fulles, i tota la vegetació, ja ho són, de verdes; la llum pren sentit des dels altres dos valors, que augmenten la saturació i la claredat del món d'Artur, i en fan un món brillant, concretant-ne així de manera visual el caràcter mitològic, feèric, màgic, tal com el vol Boorman: «lt breathes a little magic into the scene; it gives it a sense of otherworldliness» ('Això insufla una mica de màgia a l'escena; li dóna un aire ultramundà', Kennedy 1981). Raeleen Chai-Elsholz i Jean-Marc Elsholz (2015: 101-102) relacionen aquesta llum màgica amb el Drac omnipresent -i més endavant veurem com el Drac i la voluntat mitològica de Boorman estan efectivament relacionats. D'altra banda, Lesley Coote (2012: 519) i Brian Hoyle (2012: 124) coincideixen a considerar que l'ús del color en Boorman és deutor del dels pintors prerafaelites. ${ }^{17}$

El cromatisme de Perceval, en canvi, utilitza una gamma de colors vius per acostar la imatge rohmeriana a les miniatures medievals. Rohmer se serveix de les miniatures conservades del Conte du Graal per combatre la dificultat insuperable que troba d'entrada: la perspectiva cònica, donada per la naturalesa fotogràfica de la imatge cinematogràfica. Només una imatge que funcioni en els paràmetres de les imatges medievals pot casar amb l'intent de respectar al màxim la naturalesa del text original. Així, s'ha d'aconseguir una imatge finida en si mateixa — que no continui més enllà de l'enquadrament- i simbòlica. ${ }^{18}$ En això treballen, amb èxit notable, els decorats: fins i tot en les escenes d'ambientació en exterior, els fons pintats, com que no se n'amaguen, marquen

17 La relació, que assenyala Hoyle (2012: 125), de l'Ofèlia de Millais amb la Dama del Llac de Boorman és clara; la d'El cavaller del Sol de Hughes amb la batalla final d'Excalibur, no tant, és només ambiental i no escènica.

18 Coote (2012: 517) explica així aquest funcionament simbòlic: «The images in medieval art are representational, reflections of the "real". What matters is not the naturalism of the image, but what is signified. The stylized gesture reminds the viewer of the signified emotion in the natural, the "real", world, and this is what the viewer "reads"

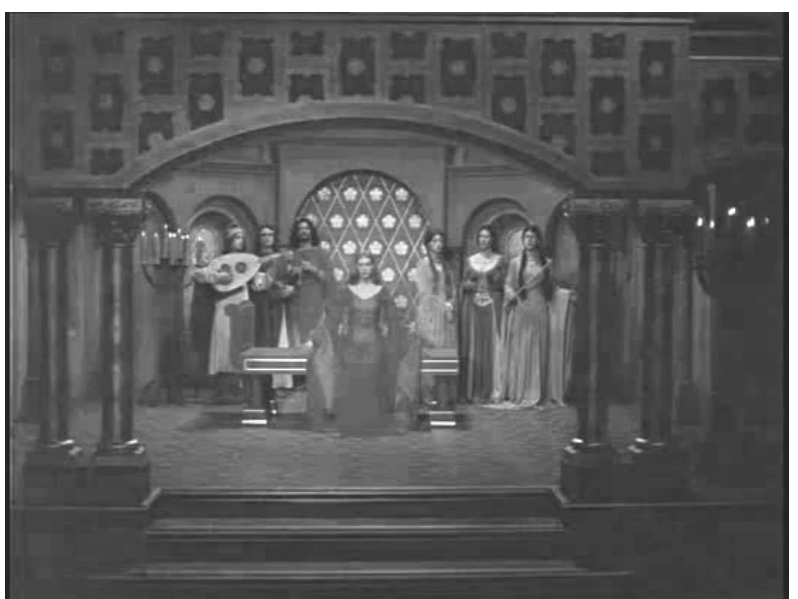

Decorats i posició de càmera treballen junts (Rohmer 1978, min. 00:45:20).

un final absolut de la imatge; però on aquest esforç més reïx és en els interiors, quan a la tasca dels decorats s'afegeix la posició frontal de càmera en pla sencer, si pot ser amb un primer terme que estableixi un marc. La distribució de les figures en l'espai perspectiu escenogràfic es fa en funció de com queden registrades en l'enquadrament bidimensional, de manera que el problema original de la perspectiva és reconduiit: la llunyania - la distància entre la càmera i els diversos personatges - es transforma en la mida de les figures sobre el pla, una mida simbòlica que, com en les miniatures medievals, varia en funció de la importància de cada personatge. A més, els elements dels decorats, sobretot els arbres, també tenen un naturalesa simbòlica, tant pel que fa a l'espècimen com al collectiu: un arbre és representat amb una figura que només simbòlicament es pot identificar com a arbre i, com a les miniatures medievals, cada una d'aquestes figures pot no significar només un sol arbre sinó un grup d'arbres, un bosc.

L'associació de la llum i el Drac és central en l'article de Chai-Elsholz \& Elsholz (2015: esp. 99-107), i s'hi basen per afirmar que Boorman fa que tot en Excalibur sigui fet de llum com a traducció cinematogràfica de la teologia de la llum baixmedieval. Que extradiegèticament tot en Excalibur és fet de llum és absolutament cert —com també ho és que la imatge cinematogràfica no és el fotograma sinó una imatge mental que resulta de la unió de fotogrames-, en Excalibur 
en qualsevol pellícula; que aquesta llum extradiegètica ho segueixi informant tot intradiegèticament (p. 102, i també p. 107) ja no és tan clar. Tot brilla, sí, però no tot és fet de llum — només el Graal és fet de llum en un determinat moment: vegeu més endavant la meva explicació de l'allegoria de Boorman-; o almenys no veig res en la pellícula que fonamenti aquesta afirmació. Si Boorman hagués volgut ser fidel a concepcions medievals, ho hauria estat en tot, també en l'estructura de Le Morte Darthur, i hauria realitzat sobre Malory l'operació que Rohmer fa sobre Chrétien. Com dic, l'ús de la llum a Excalibur es deu al caràcter mitològic amb què Boorman entén i vol entendre la matèria artúrica; el que sí que té fonament és relacionar la llum intradiegètica amb el Drac.

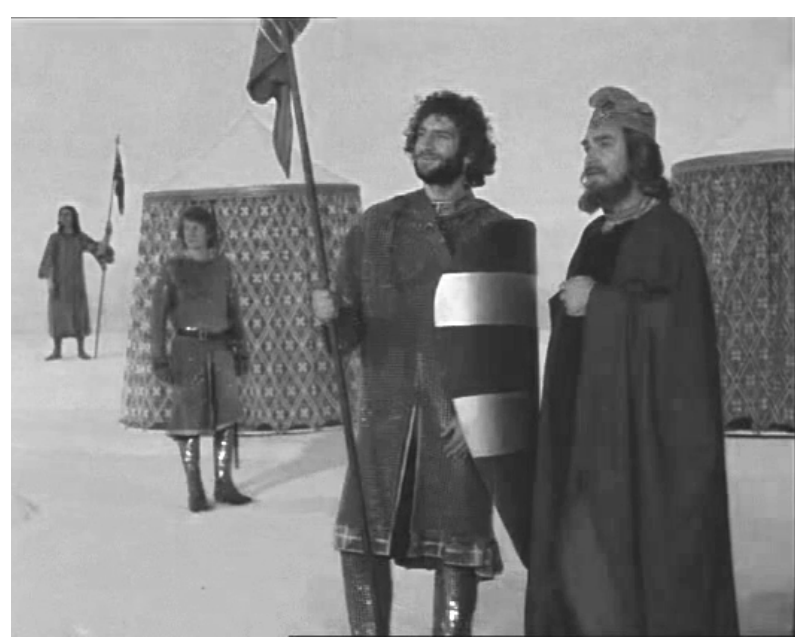

La llunyania es transforma en importància (Rohmer 1978, min. 01:28:45).

També la posada en escena collabora en aquest mateix sentit d'acostament a les miniatures. Els personatges es mouen pel decorat seguint trajectes que tendeixen al cercle, cosa que respon al doble fi perseguit. D'una banda, el cercle és una figura tancada, tal com ja hem dit que es vol que sigui la imatge; d'altra banda, com hem vist suara en el cas de les figures - personatges, arbres - , aquesta naturalesa circular dóna valor simbòlic als trajectes: una volta entorn d'un arbre pot voler dir de fet tot un viatge llarg pel mig del bosc. $^{19}$

19 Rohmer ho explica a Douchet (1978: min. 23:27). Per

\section{L'espai}

Aquest mateix espai de dimensions $X, Y$ i z reduï$\mathrm{da}$ — profunditat transformada en mida sobre el pla - inclou els somnis, les visions i revelacions. Els fets meravellosos, com tot l'episodi del Rei Pescador, succeeixen en la mateixa realitat que els fets versemblants, com l'estada al castell de Gornemant de Goort, tal com ho concebia la mentalitat medieval. En canvi, la concepció de l'espai d'Excalibur es basa en la manera perspectiva d'entendre'l que en tenim en aquest segle i des de les revolucions del Renaixement en aquest sentit: el món és un contínuum de tres dimensions $X, Y$ i z. Ara bé, aquesta terra o país on regna l'Artur boormanià d'Excalibur no pot ser situada en cap mapa científic, també forma part de la mitologia. ${ }^{20}$ Al llibre de Malory Artur és engendrat al castell de Tintaguel, que Google Maps sap situar amb la seva celeritat característica; i quan Artur arrenca l'espasa de la roca entre els cavallers que s'oposen a acceptar un escuder de baixa condició com a rei hi ha, a més dels senyors de territoris mitològics, el rei Clarivaus de Northúmbria, el rei Lott de Lothian i Orkney, el rei Idres de Cornualla, el rei Cradilmans de Galles del Nord, el rei Angwysshauns d'Irlanda i el rei Carados d'Escòcia,21 topònims aquests que figuren a les nostres guies de viatges. A Le Morte Darthur hi apareix Londres, i Camelot és Winchester (Shepherd 2004: 61). A la pellícula Camelot és Camelot.

exemple, el Via crucis de l'escena de la Passió, al final de la pellícula, consisteix en dues voltes senceres dintre de l'enquadrament. $O$ el viatge de Perceval des del castell d'Artur fins a les envistes del de Gornemant de Goort, en què «le valet sans nul arrêt | va chevauchant par la forêt, | tant qu'il advint dans une plaine | que limitait la mer lontaine», deu ser d'uns 30 metres, cobert amb un únic pla tràveling-panoràmica que dura 33 segons.

20 Sobre les relacions entre la geografia i la toponímia arturianes i les científiques, vegeu Rouse \& Rushton (2009).

21 Els senyors de terres mitològiques són el duc Escans de Candebenet, el rei Brandegoris d'Strangore, el rei Uriens de Gore, el rei Nantres de Garloth i el Rei dels Cent Cavallers, que es diu Barraunt le Apres, i no sabem d'on és. Vegeu el passatge a Shepherd (2004: 18-19). Cal completar-ho amb la p. 640 i l'índex de noms propis (p. 939). 


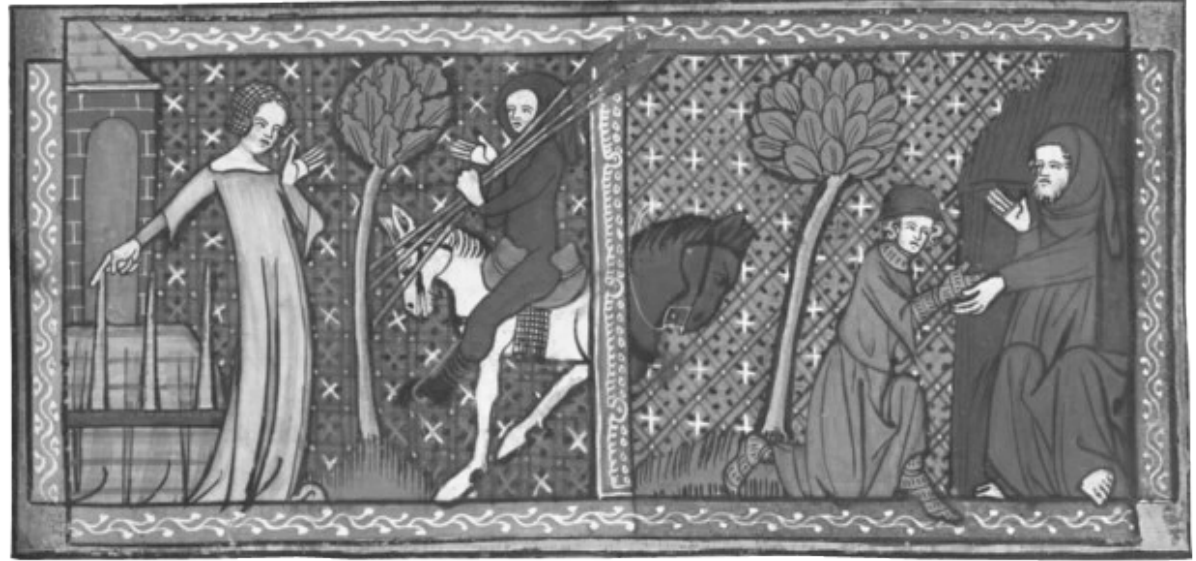

Arbres, boscos, pucelles (París, BnF, fr. 12577, f. 169, 1330?).

Per tant, l'espai d'Excalibur té tres dimensions $X Y Z$, però cal afegir-hi una quarta dimensió, adjacent i no pas interna al conjunt de les altres tres: el somni o, més en general, la ment. Quan Morgana aconsegueix sostreure el Conjur de la Creació a Merlí, l'empresona a les entranyes del Drac perquè no entorpeixi els seus plans contra Artur; abans de l'escena de la batalla final, però, Merlí podrà escapar-se d'aquesta presó XYZ a través de la dimensió somni, i s'apareixerà a Morgana en somnis - per eliminar-la i facilitar el combat a Artur (min. 01:59:02).

Aquest episodi en reelabora un de Malory, en què Merlí s'enamora de Nínive, una damisella de la Dama del Llac, i fuig amb ella. Merlí acompanya Nínive a una roca «whereas was a grete wondir, and wrought by enchauntement», i ella, amb un engany, li descobreix els secrets i el deixa atrapat sota la roca (Shepherd 2004: 78). Hi ha un ressò d'aquest enamorament del Merlí de Malory en el Merlí de Boorman, tant en la conversa amb Morgana just abans de l'acusació de Ginebra (min. 01:06:08) com en la visita a la tenda de Morgana abans de la batalla final (min. 01:58:33).

Aquesta mateixa dimensió també serveix a Lancelot o a Perceval per accedir a coneixement altrament inaccessible: amb el seu somni — psicoanalític i no pas medieval: el contingut del somni no pertany a l'espai XYZ — Lancelot sabrà que en l'amor per Ginebra «lluita contra ell mateix» (min. 01:11:41); i la doble revelació de Perceval, que funciona en dos parèntesis aliens a la situació real d'XYZ — per exemple, la primera aparició passa mentre al món XYZ Perceval s'ofega a l'arbre dels penjats-, li farà conèixer la veritat última que «Artur i la terra són un».22

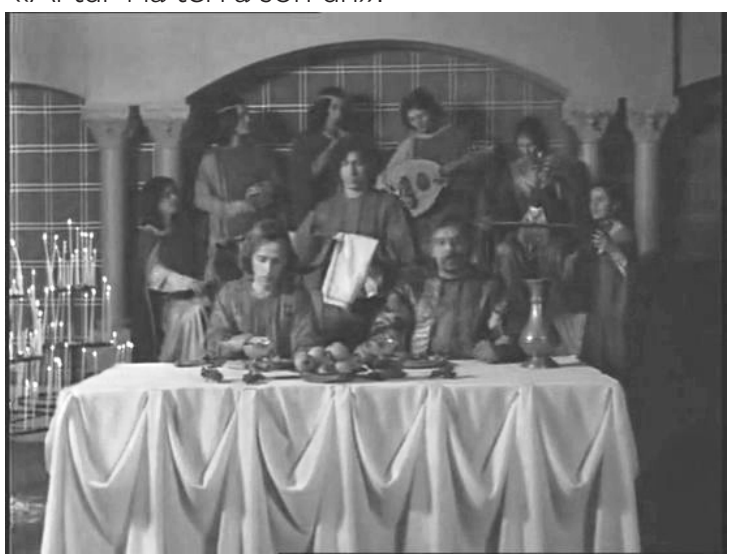

Al castell de Gornemant de Goort (Rohmer 1978, min. 00:40:29).

\section{L'alllegoria de Boorman}

Aquesta afirmació és el nucli de l'allegoria ideològica d'Excalibur. Vegem-ne el contingut, començant pel Graal i Lancelot. Cada cop que, en la revelació, Perceval entra a Camelot esdevingut Castell del Graal, una veu li formula dues preguntes: «¿Quin és el secret del Graal? ¿Al servei de qui està el

22 Per al Perceval penjat, vegeu min. 01:39:01. Al llibre Perceval mor fent d'ermità en la recerca del Graal (Shepherd 2004: 587). La revelació és al min. 01:49:18. Merlí ja ho ha dit al min. ๑o:30:18. 
Graal?»». ${ }^{23}$ | després que Perceval hagi respost la segona pregunta — «Està al vostre servei», i «Vós sou el meu senyor i el meu rei: sou Artur»— la veu insisteix en la primera — «iHas trobat el secret que jo he perdut?»-; «Síı», diu Perceval, «Vós i la terra sou un». Aquesta resposta fa que el Graal es materialitzi davant de Perceval, que el porta a l'Artur malaltís de l'espai XYZ. La frase «Artur i la

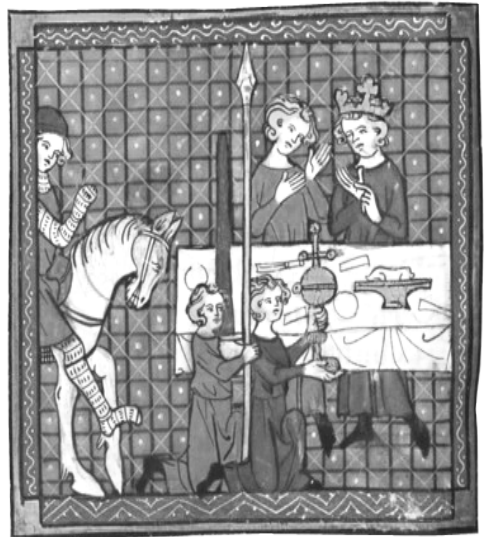

Processó del Graal i la llança que sagna (París, BnF, fr. 12577 , f. 213, 1330?).

terra són un», doncs, és «el secret del Graal».

Com bé recullen Chai-Elsholz i Elsholz (2015: 103), el Graal va apareixent al llarg de la pellícula i «enters the film subtly, most unnoticeably» ('s'introdueix a la pellícula subtilment, sense que es noti'). Ara bé, no totes les aparicions d'una copa són aparicions del Graal, com no totes les espases que apareixen són Excalibur. Les copes que hi pugui haver a Tintaguel (min. o0:06:07), que ChaiElsholz i Elsholz consideren la primera aparició del Graal, no ho són: els personatges no hi interactuen i, per tant, no es constitueixen en objecte rellevant ni passen de ser una part del decorat. El Graal apareix per primera vegada com a símbol heràldic de Lancelot, a l'escut (min. 00:46:07) i al pit de l'armadura (min. 00:47:50). Reapareix al casament d'Artur i Ginebra associat per les paraules del sacerdot a «la sang de Jesucrist», presa com a argument d'autoritat (min. 00:57:52). Chai-Elsholz i Elsholz (2015: 103) afirmen que Artur i Ginebra beuen de la copa «witnessed by

23 Boorman (1981: min. 01:39:59 i min. 01:48:45ss). all of the attendees» ('observats per tots els assistents'), però és més exacte afegir-hi «sobretot per Lancelot» (min. 01:00:48). Quan Galvany acusa Ginebra ella li diu que el perdonarà si «beu de la copa de Lancelot per compartir-ne la bondat», però Galvany refusa l'oferiment (min. 01:08:17ss).

El protagonisme del Graal culmina quan, ja identificat com a tal, el busquen els cavallers de la Taula Rodona, fins que Perceval l'aconsegueix i el porta a Artur. En aquesta recerca, el Graal és «allò que va ser perdut», «l'única cosa que pot redimir» Artur i els seus (min. 01:31:35ss), i el desencadenant de la recerca és l'afer entre Lancelot i Ginebra, consumat just després que Lancelot marxi de Camelot en el sopar posterior al Combat de la Veritat. Cal, doncs, trobar el Graal perquè Lancelot va marxar, el Graal es va perdre quan Lancelot va abandonar Artur. A l'escena d'aquest sopar (min. 01:18:40ss), Lancelot avisa Artur que «hem perdut el bon sentit» davant d'uns cavallers que fan xerinola de manera ostentosa, ${ }^{24}$ i Artur li respon elevant-lo — elevant Lancelot - a exemple pels cavallers. Finalment, durant la recerca del Graal, Perceval troba Lancelot, que s'ha fet ermità: ja no duu l'escut i l'armadura amb el Graal, però porta a les mans una copa, quan podria no portar res (min. 01:46:30). El Graal és, doncs, el símbol de Lancelot.

En la primera aparició de Lancelot, Artur el combat; abans de fer-ho, però, pregunta a Merlí «qui és aquest cavaller» (min. 00:44:37ss), i Merlí, parlant denotativament del peix que vol atrapar amb les mans però connotativament de Lancelot, respon que «se'l miri: tan bell, tan àgil». Tot seguit, Artur i Lancelot mantenen una conversa al pont (min. 00:45:05ss). Quan Lancelot diu no haver trobat cap rei prou valuós per resistir la seva espasa - després es caracteritzarà a si mateix com «el millor cavaller del món» (min. 00:51:52) — Artur li respon que «això és una fatxenderia salvatge», i que «li manca la humilitat del cavaller»; Lancelot el corregeix dient que «No és fatxenderia, és la meva maledicció». És a dir, quan es proclama el

24 Norris J. Lacy (2002: 35) també es fixa en l'avís de Lancelot. Coote (2012: 520) parla de «the negative forces of rumour and jealousy which have entered the society of the Round Table [...] through luxury and indolence brought on by success». 
millor cavaller del món no s'està sobrevalorant; dir que és el millor cavaller del món és el màxim d'humil que pot ser. Ermità, Lancelot blasma Perceval, i parla contra els cavallers perquè «a causa de llur orgull [=fatxenderia] i de llur pecat Déu ha deixat el món». Afirma que «han volgut prendre el lloc de Déu i Crist ens ha abandonat» (min. 01:46:44) i reclama a Perceval, que duu l'armadura bruta de fang, i als cavallers en general que siguin humils. Ja al seu combat amb Artur, l'armadura de Lancelot era neta i brillant (min. 00:47:45), mentre que la d'Artur, que és a qui realment «manca la humilitat del cavaller» en aquella escena, era bruta i mat.

Lancelot és bell, és àgil, és bo —hem vist que Ginebra ho deia a Galvany-, és exemple de cavallers, és humil i és - mal que li pesi- el millor cavaller del món. També és honrat:25 quan Galvany acusa Ginebra, Artur estableix les normes del Combat de la Veritat i argumenta que «cap cavaller que sigui fals pot vèncer en un combat contra un que sigui honrat» (min. 01:09:45); el Combat el guanya Lancelot, i Galvany retira l'acusació (min. 01:16:40). Més endavant, preguntat per Artur per «quina és la qualitat més important del cavaller», Merlí respon que és «l'honradesa. [...] Quan un home menteix mata un tros de món» (min. 01:19:19ss). El mateix Lancelot, orant per preparar-se pel Combat contra Galvany, afirma que per Ginebra «ho sacrificaria tot» i assenyala com a màxima qualitat seva «l'honor, l'honradesa» (min. 01:10:43ss). Aquestes característiques del cavaller modèlic són contingudes en «el secret del Graal»: «el rei i la terra són un» vol dir que el rei s'ha de donar als altres, als seus súbdits —els súbdits estan lligats a la terra, en són part-, ha de ser franc amb ells; ha de ser humil i honrat.

25 En anglès, true, que vol dir tant 'in accordance with fact or reality' i 'accurate or exact' com 'loyal or faithful'; $O D E$, s.v. true, encara afegeix: «origin. Old English trēowe, trŷwe 'steadfast, loyal'; related to [...] German treu», que vol dir zuverlässig, 'lleial'. L'antònim de true és false, que també té el doble valor: 'not according with truth or fact; incorrect', 'illusory; not actually so'; i 'disloyal, unfaithful' (ODE, s.v. false). En català, honrat reuneix els dos significats de true, i en tenim prou amb fals per recollir els de false.
Vegem ara quin lloc ocupen Excalibur i Ginebra en l'allegoria de Boorman. A Artur davant de Lancelot li manquen qualitats del bon cavaller - justament les té no dintre seu ni a la seva tropa sinó davant seu personificades en Lancelot, que lluita a la defensiva i procura no fer mal a Artur - i així la seva vanitat i la seva ràbia fan que trenqui Excalibur (min. o0:49:21). Excalibur és l'Espasa del Poder, i la seva funció és «guarir, no pas ferir»: ho diu Merlí a Uther a l'escena inicial (min. o0:02:53) i ho parafraseja Artur quan s'adona de la seva manca d'humilitat un cop resolt el combat amb Lancelot. El penediment d'Artur el duu a afirmar que «No sóc res», i aquesta expressió d'humilitat màxima fa que la Dama del Llac emergeixi i retorni Excalibur de nou sencera, guarida i ja no ferida. Lancelot torna en si i jura fidelitat a Artur fent un petó a la punta d'Excalibur (min. o0:50:12ss).

Aquesta part final del combat amb Lancelot no és l'única escena que passa dins l'aigua. Ja abans Artur ha combatut Uriens mig submergit al fossar del Castell de Camelyard. Això connecta les dues escenes, que contrasten per l'ús d'Excalibur. Davant de Lancelot, Artur fereix amb Excalibur i això trenca l'espasa; davant d'un Uriens que no vol sotmetre-se-li perquè només és un escuder, Artur cedeix Excalibur a Uriens perquè l'adobi a cavaller (min. oo:38:47ss), confia en Uriens, es dóna a Uriens. Aquest acte de confiança, amor i guarició contrasta, no només amb l'embat contra Lancelot, sinó també amb la reticència d'Uther a cedir davant del Duc de Cornualla en la negociació de la pau a banda i banda d'un rierol (ha de ser Merlí qui exhorti Uther a cedir). ${ }^{26}$ Precisament, aquesta negociació de la pau ha estat menyspreada per Uther en l'escena inicial: «Parlar és cosa dels que estimen», diu, i ho contrasta amb una expressió d'ambició del poder (min. o0:03:00).

Les proeses d'Artur a la batalla de Camelyard, que culminen amb l'èxit de confiar en Uriens i prestar-li Excalibur (i tanquen el litigi amb els cavallers que no el volien reconèixer rei), un èxit que ni Merlí no havia previst (min. o0:39:52),

26 Boorman (1981: min. o0:04:23ss). També ho nota Coote (2012: 520). 
són observades atentament per Ginebra (min. oo:37:42). El personatge de Ginebra, que és prefigurat en Igraine, s'associa amb l'amor: és l'amor maternal que mou Igraine a consolar Morgana (min. oo:13:11), i a exclamar-se quan Merlí li pren el fill (min. oo:18:39); al ball després de la batalla de Camelyard Ginebra dóna un pastisset a Artur, i es deixa entendre que el pastisset porta substàncies afrodisíaques (min. 00:43:05); i quan davant l'acusació de Galvany Artur diu a Ginebra que no la pot defensar perquè «les seves lleis han de vincular tothom [és a dir, han de ser vinculants per a tothom], d'alta i de baixa condició, o deixen de ser lleis» (min. 01:10:17), que abans que marit ha de ser rei, ella respon amb un compungit i desorientat «iabans que l'amor?» (min. 01:10:25) Tant Igraine com Ginebra seran al centre d'un triangle n'hem de dir amorós.

Ginebra és filla de Leondegrance de Camelyard. Més enllà de la de Sir Hèctor i Sir Kay, pare i germà adoptius, la primera fidelitat que obté Artur en treure Excalibur de la roca és la de Leondegrance (min. o0:29:15). Així, i amb Ginebra observant com Artur sotmet Uriens des de la muralla de Camelyard, s'associa l'obtenció d'Excalibur amb l'obtenció de Ginebra. Més endavant, quan Artur clava Excalibur entre Lancelot i Ginebra nus, és Ginebra qui es queda Excalibur (min. 01:28:48) i la guarda fins que la retorna a Artur (min. 01:53:44). Tal com el Graal és el símbol de Lancelot, Excalibur és el símbol de Ginebra, de l'amor. «El rei i la terra són un» també vol dir que el rei ha d'estimar els seus súbdits, que és exactament el que fa Artur quan dóna Excalibur a Uriens perquè l'adobi a cavaller; com que el gest és encertadíssim des del punt de vista del principi d'unitat del rei i la terra, Uriens no pot sinó cedir, adobar Artur i sotmetre-se-li. Així, «el secret del Graal» també és «el secret d'Excalibur», perquè obtenir l'espasa, com obtenir el Graal, dóna accés a aquesta veritat última: quan Artur treu Excalibur de la roca Merlí li diu que «Tu seràs la terra i la terra serà tu» (min. oo:30:18). De la mateixa manera, tal com Excalibur és l'Espasa del Poder també el Graal és la Copa del Poder: són l'única espasa i l'única copa que permeten l'accés al poder veritable. Quan Mordred porta Perceval al castell de sa mare, Morgana li ofereix una copa perquè en begui, i li diu que «hi ha moltes copes de què beure al món»: és a dir, hi ha molts poders alternatius al del Graal _l'existència del qual, de fet, Morgana nega. Però cap d'aquests no és el poder veritable, perquè aquests són tots «plaers», és a dir, ambicions. Perceval es nega a acceptar que el poder veritable, el Graal, no existeixi, i per això el pengen (min. 01:36:38ss).

Per ser el bon rei que està destinat a ser, Artur necessita Excalibur/Ginebra _l'amor — i el Graal/Lancelot -la bondat, la humilitat, l'honradesa. Li calen tots dos: la primera absència de Lancelot farà que Galvany acusi Ginebra i es desencadeni així la caiguda d'Artur. En el seu primer ascens al poder Artur no podrà dir que «les guerres s'han acabat» i que s'ha assolit l'harmonia d'«Una terra, un rei! La pau!» (min. 00:53:10) fins que a més d'Excalibur/ Ginebra no tingui també Lancelot. De la mateixa manera, quan recupera el poder és perquè Perceval li ha dut el Graal i Ginebra li retorna Excalibur, i no podrà vèncer en la batalla final contra l'exèrcit de Mordred fins que no arribi Lancelot (min. 02:04:17ss).

Que tots dos objectes/personatges són necessaris per accedir al poder veritable i a l'exercici del bon govern, acaba volent dir que són una mateixa cosa (també se n'adonen Chai-Elsholz \& Elsholz 2015: 104). De fet, la frontera que els separa no és del tot nítida: és Ginebra qui dóna la copa de Lancelot a Galvany, i ella mateixa beu d'una copa idèntica quan Lancelot marxa de Camelot per segona vegada (min. 01:20:03); la copa del casament de què beuen Artur i Ginebra sota la mirada de Lancelot materialitza l'honradesa de 
la relació, però també l'amor que els uneix, i ja he assenyalat que Lancelot fa un petó a Excalibur quan promet fidelitat a Artur. La conclusió del somni de Lancelot és que «lluita contra ell mateix »: ho diu despertant-se del somni amb l'espasa — no amb Excalibur però sí amb la segona espasa del Regne - clavada al costat, i just abans del somni, pregant, ha demanat a Déu que el purgui de l'amor de Ginebra. La lluita amb ell mateix és la lluita d'un Lancelot nu —el de l'escena posterior amb Ginebra quan Artur va a clavar Excalibur entre els dos- contra un Lancelot cavaller, amb armadura, el que resava abans del somni i demanava ser alliberat de l'amor, i que ara vol eliminar el Lancelot nu: del somni en surt, bé que ferit, el Lancelot nu, no pas l'armat que hi ha entrat (min. 01:10:54Ss). Al Combat de la Veritat Lancelot venç Galvany, però cau en una profunda letargia: Artur exigeix a Merlí que el curi, i per fer-ho, a més de dir el Conjur de la Creació, Merlí posa la mà de Ginebra sobre la ferida de Lancelot (min. 01:16:58ss); és Ginebra qui cura Lancelot, perquè quan ell es desperta del seu mal només l'acompanya ella (min. 01:18:18). L'afer entre els dos és, doncs, més que amor —i més que luxúria-, l'atracció entre les parts d'un tot. Perquè s'atreuen i es completen queden ullpresos l'un de l'altre en el moment de veure's per primer cop (min. o0:55:38).

És perquè els té tots dos que Artur pot ser un bon rei i portar esplendor al seu reialme: ni Uther ni Mordred no els tindran tots dos. ${ }^{27}$ Potser Uther era un bon cavaller, però menyspreava l'amor. I la seva passió per Igraine no era amor, era luxúria - luxúria d'Uther, no pas d'Igraine, que és passiva a més no poder-, una forma d'ambició: els gestos dolços d'lgraine amb Morgana són violentats per la brusquedat amb què Uther —amb aspecte de Cornualla - agafa Igraine pels braços, li encasta els llavis a la boca i la despulla (min. 00:13:38ss). Igualment, Mordred només té ambició — exigeix a Artur que li cedeixi el control de la terra-, i rebutja l'amor que li ofereix Artur perquè «aquesta és l'única cosa

27 Segons Coote (2012: 520): «Mordred is thus [...] the son who displays his father's negative qualities. Arthur, on the other hand, displays Uther's positive qualities». La cursiva és seva. teva que no vull» (min. 01:42:15ss). De fet, l'ambició de Mordred no és més que una extensió de la de Morgana. Si Artur amb Ginebra i Lancelot és el bon govern, Morgana és el mal govern, guiat per l'ambició i la set de venjança: és un personatge calculador i ressentit durant tota la pellícula, que dedica tota la vida a aprendre màgia per venjar l'engany d'Igraine per part de Merlí, i que planeja fins i tot amb qui ha de fer l'amor per tenir un fill que li serveixi de candidat al tron. Just abans d'engendrar Mordred, Morgana proclama que «trobarà un home per fer néixer un déu», ${ }^{28}$ volent dir un ésser extrahumà perquè no tindrà sentiments propis ni tampoc autonomia respecte l'ambició de sa mare. Fins i tot Artur és el mal govern quan la gelosia el fa actuar amb egoisme -i per tant oblida el principi que «el rei i la terra són un», ja no es dóna als altres, ja no és humil, sinó que segueix els passos de Galvany, altre robot teledirigit de Morgana, menys perfecte que Mordred — davant de l'afer entre Lancelot i Ginebra (min. 01:26:29).

Al Combat de la Veritat, doncs, s'hi enfronten el bon govern d'Artur i el mal govern de Morgana, i el primer té d'entrada totes les de perdre, perquè ningú el defensa: no hi ha esperança fins que intervé Perceval (min. 01:12:20), que és el peó de Lancelot.29 Perceval és el personatge central de la recerca del Graal a Excalibur: el veiem recórrer el món durant deu anys i un dia (min. 01:32:515s) —li ho diu Morgana perquè ell n'ha perdut el compte (min. 01:37:08) — abans de

28 Boorman (1981: min. 01:28:03). Aquest déu, Mordred, té més èxit en el llibre que en la pellícula en el seu intent de prendre el poder al seu pare. Al llibre fins $i$ tot sembla que hi hagi d'haver un acord entre els dos, pel qual Mordred accepta esperar a la mort natural d'Artur per regnar, però un escurçó inesperat desencadenarà la batalla final en què Mordred morirà i Artur quedarà ferit de mort (Shepherd 2004: 684-685).

29 I també el peó de Ginebra, doncs. Serà ell qui s'encarregui de retornar Excalibur a la Dama del Llac al final de la pellícula, i no voldrà que es perdi o que se'n perdi l'esperança — ho veurem de seguida-; per això Merlí diu, quan Artur trenca Excalibur, que «Has trencat el que no podia ser trencat. L'esperança s'ha trencat»» (min. 00:49:37). Explica Hoyle (2012: 121) que al primer esborrany conservat del guió d'Excalibur «Perceval is the illegitimate son of Lancelot and Guinevere». 
trobar Mordred, i tants anys més després, $3^{\circ}$ els necessaris perquè Mordred passi de ser nen a un home fet i dret (min. 01:41:12). En aquests vint anys no para de buscar el Graal, no perd mai del tot l'esperança, encara que s'exclami que «no el trobarem mai» (min. 01:34:06); i rebutja l'afirmació de Morgana que el Graal no existeix. Uriens moribund li diu que «ets l'últim de nosaltres» i, quan comencen a sentir-se els gemecs de la processó de desesperats de Lancelot, que «et criden a tu» (min. 01:45:14). Els desesperats criden Perceval, que és, doncs, l'esperança. Ho diu ell mateix sortint del riu on l'han tirat els desesperats: «No puc perdre l'esperança, Lancelot. És tot el que tinc» (min. 01:48:08).

Per això, Perceval podrà trobar el Graal. No en la recerca per l'ample món, sinó cap endins. Ho recullen Chai-Elsholz i Elsholz (2015: 105): en encarregar la recerca als seus cavallers, Artur els havia dit que busquessin «a l'extrem de cap endins» 3. Perceval, penjat a l'arbre pels sequaços de Morgana, i incapacitat doncs per recórrer el món cap enfora, descobrirà que el pot recórrer cap endins, i tindrà la primera visió (min. 01:39:235s). Primer no entendrà ben bé què passa - encara porta el pes de la infructuosa recerca exterior, denotat per la seva armadura bruta i feixuga - tindrà por, no sabrà respondre a les preguntes que li fan i fugirà; però penjant, dins de la visió, del capdamunt del pont llevadís s'adonarà que està veient un Graal de llum —i això ho marquen dos plans detall del Graal quan Perceval ja ha sortit del castell però encara no ha caigut: el moment s'allarga marcant l'operació mental de Perceval (min. 01:40:20ss). Ja ha descobert com accedir al Graal, que és una idea,32 i això li dóna dret a no morir escanyat a l'arbre; però no ha sabut respondre les preguntes i per tant haurà d'errar uns deu anys més.

Però es toparà amb Lancelot, que l'escridassarà exigint-li humilitat i honradesa — perquè

\footnotetext{
30 Hoyle (2012: 122) diu que són nou anys.

31 Els diu que busquin el Graal «als laberints dels boscos fins a l'extrem de cap endins» (min. 01:31:47). En una escena anterior Merlí ha anomenat la ment «un bosc encara més enrevessat» (min. 01:18:08).

32 També ho comenten Chai-Elsholz \& Elsholz (2015: 105 i 107).
}

creure's Déu quan un no l'és és vanitós i deshonest. El seguici de Lancelot el llançarà al riu, estomacant-lo, sí, però deixant-lo a la mercè de l'aigua purificadora:33 s'ofega de nou, ara ben bé pel pes de l'armadura — abans era pel de l'armadura i pel del seu cos-, però se la treu i reneix, net, tal com és - tal com era quan Lancelot el va prendre com a escuder - - lliure de vanitat i falsedat, humil i honrat com li acaba de reclamar Lancelot, i segur d'ell mateix.

Cal, doncs, que matisem el que hem dit en parlar de les armadures en Boorman; cal que ho matisem, però poc, perquè Boorman efectivament sembla creure que l'armadura fa el cavaller i, a la vegada, porta l'armadura a ser el símbol de la vanitat i la manca d'honradesa dels mals cavallers. Potser podem resoldre aquesta —inomés aparent? - contradicció precisant que l'armadura és símbol de les bones qualitats del cavaller —i doncs, sí, l'armadura fa el cavaller- i distingint tot seguit si l'armadura és neta com una patena i brillant -i en aquest cas el cavaller que la duu és humil i honrat-o si és bruta de fang -i aquesta brutícia denota un embrutiment moral. Diu Marino (2004: 25) que a Le Morte Darthur «humility is the lesson to be learned, especially when the best worldly knight [Lancelot] laments his failure in heavenly adventures on account of his sin»; «That the knights are repeatedly stripped of arms and horses indicates that this adventure is to be undertaken with spiritual weapons».

Ara ja sap quina és la idea del Graal, «el secret del Graal». Sortint de l'aigua tindrà la franquesa de dir-nos que ell és l'esperança i podrà tornar a accedir al Castell del Graal, on respondrà les preguntes adequadament: el Graal de llum es tornarà Artur i Artur es tornarà Graal material, a l'abast de la seva mà (min. 01:48:18ss).34 L'esperança, la perseverança de Perceval ha tingut èxit.

33 Chai-Elsholz \& Elsholz (2015: 105) subratllen el poder guaridor de l'aigua a Excalibur. I tant Whitaker (2002: 46) com Rouse \& Rushton (2009: 222-223) assenyalen el valor de frontera entre el mundà i l'ultramundà que els celtes atribuïen a l'aigua.

34 A Chai-Elsholz \& Elsholz (2012: 100) sembla que hi hagi un embolic en l'ordre dels estats del Graal: «the Grail that appears to Perceval is a gleaming chalice, then a 
Coote (2012: 521) es pregunta per què ha de ser Perceval el cavaller central de la recerca del Graal, i apunta que potser Boorman segueix el Perceval le Gallois de Rohmer. Però no cal passar per Rohmer i podem suposar que Boorman basa l'atribució d'aquest paper a Perceval directament en el Conte de Chrétien de Troyes. En tot cas, l'allegoria de Boorman demana que l'última esperança en totes les operacions sigui Perceval. Igualment, per a Marino (2004: 3) «Perceval's defense of Guenevere [al Combat de la Veritat] does not mix well with his [...] role as chief Grail knight»»; però, ben al contrari, els dos papers sí que casen, i molt bé, perquè Perceval és l'esperança.

Perceval tindrà una última intervenció, que en bona lògica només podia ser confiada a l'esperança.

Després de clavar Excalibur al pit de Mordred, Artur ordena a Perceval que retorni l'espasa al llac.

Perceval no ho farà ni voldrà fer-ho, perquè «Excalibur no s'ha de perdre», ha de seguir disponible pel futur; però obeirà quan Artur li asseguri que «un dia vindrà un rei i l'espasa tornarà a sorgir». Hi ha, doncs, esperança perquè el bon govern torni amb la seva esplendor.35 La barca amb les tres dames s'enduu Artur a Avalon, però en aquestes ribes queda Perceval (min. 02:07:47ss).

Tot això passa al món del Drac, que «és a tot arreu, ho és tot» (min. o0:32:11).36 Ens iniciem en el coneixement d'aquest món de la mà de Merlí, que l'interpreta per a Artur i per a nosaltres. El Drac és un tot uniforme, relacionat amb la na-

gleaming Arthur, and lastly a penetrating gleam with no physical shape». Lacy (2002: 38), en canvi, sí que els diu en ordre: «from a chalice into a luminous vision of an Arthur in armor, and then back into the chalice, but this time it is not an image but the object itself: the vessel that can be grasped by Perceval».

35 Davidson (2007) desenvolupa les concepcions de Boorman quant al retorn del bon govern, notablement amb la intervenció de la memòria i el record d'un bon govern passat.

36 Coote (2012: 521) explica que la concepció del Drac «[connecta] to Geoffrey of Monmouth's Prophecy of Merlin, in which the British and the invading Saxons are represented by a red and a white dragon». turalesa, en una mena de doctrina budista molt semblant a la de la Força d'Star Wars — com la Força, el Drac també té un costat fosc, que és el de Morgana i el mal govern-, que alhora concorda perfectament amb la idea d'espai com un contínuum que ja he assenyalat.37 El Drac és el signe heràldic d'Artur _ el cognom del seu pare és Pendragon.

Només hi ha tres personatges que puguin desclavar Excalibur. Uther la clava a la roca, i només Artur aconsegueix treure-la'n; Artur la clava entre Lancelot i Ginebra, i Ginebra la pot desclavar, perquè escenes després la té al convent; Artur la clava al pit de Mordred, i veiem com Perceval la n'arrenca. Artur pot desclavar Excalibur perquè és l'elegit, Ginebra perquè és l'amor i Excalibur n'és el símbol, i Perceval perquè és l'esperança del retorn del bon govern.

També ho és, però, de Merlí: al capdamunt de la seva vara hi lluen dos dracs (min. oo:10:38) i, quan Merlí diu a Morgana que miri els ulls del Drac i perdi tota esperança, està fent referència als seus propis ulls, que s'han tornat vermells; i poc després, quan Artur clava Excalibur entre Lancelot i Ginebra i això comporta que l'espasa travessi de mig a mig el tors de Merlí, aquest diu que Excalibur s'ha clavat a la columna vertebral del Drac (min. 01:26:19ss). Merlí és la cara visible del Drac, si no és que directament és el Drac. Que el Drac sigui a tot arreu deu tenir a veure amb el caràcter perifèric de Merlí jo diria fins i tot que frega la invisibilitat als ulls de gairebé tots els personatges - , que observa Coote (2012: 521): Merlí hi és i no hi és. I Roberta Davidson (2007: 71) nota que «there are striking similarities between the character of Merlin and imagination itself» ('hi ha similituds molt potents entre el personatge de Merlí i la Imaginació'). Així, en Merlí convergeixen l'espai XYZ i la dimensió somni o ment. Al somni iniciàtic d'Artur, Merlí li diu, mentre Artur s'adorm a la seva es-

37 La primera entrega de la saga intergalàctica va estrenar-se el 1977, i la segona, en què Yoda instrueix Luke Skywalker i li explica què és la Força, el 1980. Totes dues, doncs, anteriors a Excalibur, i en tot cas totes de la mateixa dècada. Sobre la natura del Drac, vegeu Davidson (2007). 
patlla, que «dormi i reposi als braços del Drac, i que somiï» (min. oo:32:32); ja li ha dit que dor

Whitaker (2002: 47) també recull l'associació heràldica. En prendre les regnes del reialme per anar a ajudar Leondegrance, Artur parla als cavallers fidels amb la bandera del drac de fons (min. 00:34:41); hi ha escultures de dracs a l'entrada de Camelot (min. 01:03:41 i 01:05:30); i una bandera amb un drac presideix el discurs santcrispinesc que Merlí pronuncia als cavallers després que Artur hagi dit «Una terra, un rei! La pau!» i abans que digui que crearà la Taula Rodona (min. 00:53:45). El nom del pare significa 'Ploma de drac'; no pas Pandragon 'drac que ho és tot' com vénen a dir Chai-Elsholz \& Elsholz (2015: 108). Ni els celtes, ni Monmouth, ni Wace, ni Chrétien, ni Malory no sabien pas grec per llegir l'arrel de паs, пабa, паv (паvт-) a l'inici del cognom d'Uther. doncs, la naturalesa, el Drac, el tot, la imaginació, el somni, el mite, ${ }^{38}$ el món d'Artur: per això ell i Artur comparteixen l'heràldica del Drac. Merlí és la pellícula mateixa, que originalment es deia Merlin lives (Hoyle 2012: 120), i la voluntat mitològica de Boorman. 39

\section{Estructures}

Així, amb Merlí com a node, s'articulen el participant allegòric i el participant mitològic d'Excalibur. Parlem ara del mitològic. Com hem comentat més amunt, Boorman vol generar les imatges dels punts clau del mite artúric. Diu Hoyle (2012: 117 que mentre elaborava el guió d'Excalibur Boorman es va plantejar de filmar només parts concretes de la llegenda, però que al final va decidir explicar-la tota, «from Arthur's conception to his death» ('des de la concepció d'Artur fins a la seva mort'), tot i mantenir sempre el determini d'incloure especialment les escenes més conegu- mi quan se l'ha endut en braços del castell de Tintaguel, contra la voluntat i els crits d'lgraine (min. oo:19:02). L'escena de la iniciació al bosc en té una de simètrica al final, abans de la batalla contra l'exèrcit de Mordred, quan Artur puja sol al monument que sembla Stonehenge, en què Merlí es defineix com «un somni per alguns, un malson per d'altres.» Artur li ha demanat ajuda perquè no pot imaginar «cap estratègia de guerra per enganyar Mordred i Morgana» (min. 01:55:32ss); per això li cal Merlí, la imaginació, que, alliberat, anirà al campament de Morgana i farà que el propi orgull la perdi. Pot fer-ho perquè el somni és la seva dimensió. A Stonehenge Merlí assegura que Artur és «a la terra dels somnis», és a dir, «als braços del Drac», i de nou convergeixen l'espai XYZ i els somnis. Merlí és,

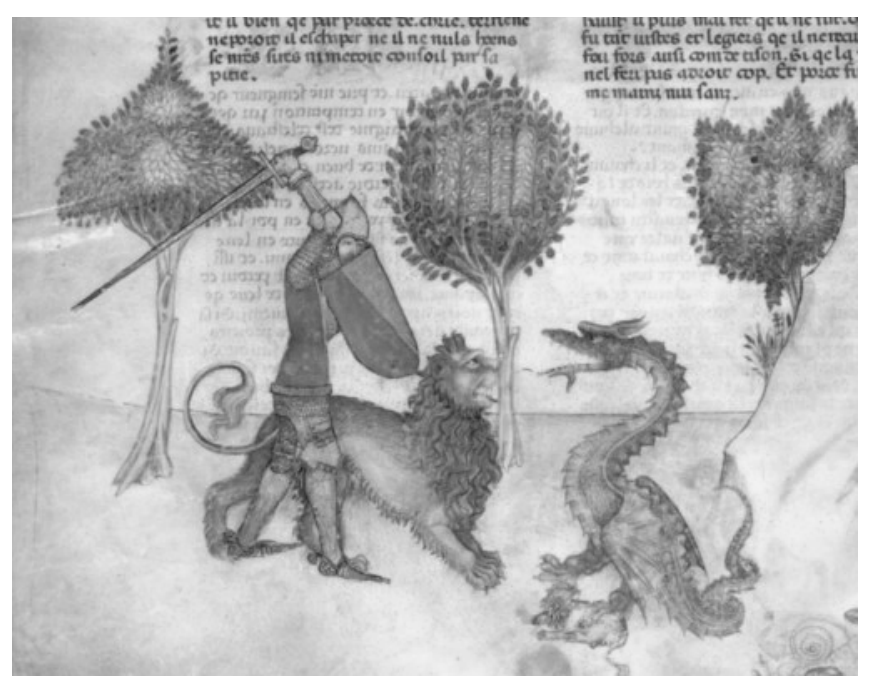
des, perquè el primer text de referència que pren Boorman és el coneixement de la matèria artúrica que té el públic a qui adreça la pellícula, i el que fa és, doncs, «tell a story that corresponds at least in major respects to the audience's understanding of orthodox Arthurian fact» ('explicar una història que es correspongui almenys a grans trets amb la manera com el públic entén el fet artúric canònic').40 Rider et al. (2002) ho centren en el públic angloamericà: Boorman, diuen, ha de respondre a les expectatives d'aquest públic. ${ }^{41}$ Sigui com sigui, el

38 Hoyle (2012: 129) també associa Merlí al mite.

39 Davidson (2007: 73) també arriba a Boorman des de la imaginació passant pel Drac i Merlí.

40 Ho diu Norris Lacy, citat per Rider et al (2002: 159, n. 17). 41 «For a modern English-speaking audience [...] the Arthurian legend serves as a means of quasi-historical 
En Malory hi ha un gust per les enumeracions de personatges; com que cadascun d'aquests personatges té un nom concret i com que inesperadament s'expliquen anècdotes d'aquest cavaller o es donen més dades d'aquell d'allà, i qualsevol d'ells pot assumir més paper en algun episodi, tots acaben sent singularitzats; això fa que el lector quedi poc o molt desorientat per la infinitud de personatges diferents. Per exemple: «So cam in the knyghtes of Sir Launcelottis kyn [...] Sir Lyonell, Sir Ector de Marys, Sir Bors de Ganys, Sir Blamoure de Ganys, Sir Bleoberys de Gaynys, Sir Gahalantyne, Sir Galyhodyn, Sir Menaduke, Sir Vyllars the Valyaunte, Sir Hebes le Renowné —all thes were of Sir Launcelottis kynne- - ... Sir Sagramour le Desyrus, Sir Dodynas le Saveage, Sir Danydan, Sir Brewne Le Noyre (that Sir Kay named La Cote Male Taylé), and Sir Kay le Senesciall, Sir Kay d'Estraunges, Sir Mellyot de Logris, Sir Petipace of Wynchylsé, Sir Galleron of Galway, Sir Melyon of the Mountayne, Sir Cardoke, Sir Uwayne les Aboutres, and Sir Ozanna le Cure Hardy. Than cam in Sir Ascamour, and Sir Grummor Grummorson, Sir Crosseleme, Sir Severause le Brewse (that was kalled a passynge stronge knyght» (Shepherd 2004: 640); al cap de poques línies ja hi ha una altra enumeració semblant. A Excalibur tota aquesta colla de Sirs són una massa uniforme d'armadures desenfocades que decoren els plans generals i les regions exteriors de la profunditat de camp; Hoyle (2012: 128) recull que Boorman podria haver arribat a aquesta massa uniforme d'armadures «inadvertently».

component o participant mitològic d'Excalibur té una formulació de base del mite artúric, amb uns moments clau, que podríem enunciar així: el rei llegendari Artur va arrencar l'espasa Excalibur de la roca, es va casar amb Ginebra - que li va ser infidel amb Lancelot-, va instaurar la Taula Rodona, i els seus cavallers van estar buscant in-

reflection [i] refers to a dim, mythological past, and is thus a statement about the way things were, might have been, or should have been [... i també] about the way present-day Anglo-American culture is, might be, or should be» (Rider et al 2002: 150). Per tant, «an Anglo-American audience [...] is [...] less likely to approve any innovations introduced by the director» (Rider et al 2002: 159, n. 17). fructuosament el Sant Graal. És el participant mitològic el que la seqüència de textos inicial traeix (min. 00:00:30ss), tant pel contingut —i subratllem especialment el mot Legend- com per la forma, amb l'accent expressiu situat amb la música sobre el nom d'Excalibur.

Aquesta formulació de base, que és abstracta, és portada a la concreció per intervenció d'un segon participant, Le Morte Darthur de Malory, que li dóna caràcter escènic — visible. Per exemple, per fer que Artur sigui llegendari Boorman recorre a l'engendrament d'Artur en la unió d'Uther amb Igraine. $\bigcirc$ per introduir el personatge de Lancelot - perquè no aparegui del no-res i perquè quedi singularitzat respecte dels altres cavallers - es pren l'episodi en què Artur surt de la Cort per anar a lluitar contra el rei Pellenor, en què un escuder arriba a la Cort portant un cavaller ferit de mort, diu que l'ha mort Pellenor, que s'ha installat prop d'una font i, després d'enviar-hi Girflet i que Girflet sigui vençut, Artur decideix d'anar-hi ell acompanyat de Merlí; el combat començarà amb una justa, seguirà a peu amb les espases i acabarà amb l'espasa d'Artur trencada (Shepherd 2004: 33-36), tal com passa a la pel·lícula en l'escena de presentació de Lancelot (min. o0:43:58).

El participant mitològic i el participant concretiu articulen una successió de fets, una història o narració, que transmet el contingut del participant allegòric —en què també s'inclou tot el que Boorman treu de Tennyson i Weston.

El participant allegòric podria ser pres com un medievalisme de Boorman —a l'Edat Mitjana tot pot ser llegit al|legòricament_- però d'alllegories se n'han fet sempre: la de Boorman no respon a una voluntat d'acostament al medieval tal com el seu interès artúric no deriva en primera instància d'una font medieval sinó del coneixement de la matèria en la seva contemporaneïtat: Boorman arriba a Malory només en un segon temps.

Alhora, la història o narració que s'articula respecta les directrius del quart participant, diguem-ne argumental. Aquest quart participant aporta el patró de guió estàndard hollywoodesc, és a dir, la distribució en tres actes ${ }^{42}$ i seguint les etapes del cicle de l'heroi enunciat per

42 Vegeu Hoyle (2012: 121): «Their [de Boorman i el seu 
L'associació, centrada en el Rei Pescador, de la salut del rei i el benestar de la terra i dels súbdits ja és present en el Conte de Chrétien de Troyes. El que ve de Weston, doncs, és la relació d'aquesta imatge amb un mite de la fertilitat i amb la naturalesa. Diu Marino (2004: 39): «Weston claims the Grail [...] was originally part of a pagan fertility myth connecting the prosperity of the land and the health of its king, who is known as the "Fisher King" in the Arthurian texts. When the king is wounded the land is blighted, a wasteland, and healing only comes by way of a quester who asks what ails him and steps in as the new king». Lacy (2002) explica l'operació de Boorman —que Hoyle (2012: 122) atribueix al guionista Rospo Pallenberg- com la fusió d'Artur no només amb el Rei Pescador, sinó també amb el Rei del Graal, és a dir, aquell que s'alimenta del contingut del Graal. I a Coote (2012: 522) no li cal parlar de Weston ni del Rei Pescador per explicar la identificació del rei i la terra; en té prou assenyalant-ho com una «medieval perception of kingship».

Joseph Campbell a The Hero with a Thousand Faces (les crides successives a l'aventura, la trobada amb el mentor, el pas del llindar de l'aventura, l'estada al ventre de la balena, i totes les altres fins al descobriment de l'elixir i el retorn messiànic que canvia el món) i la necessitat imperiosa que hi hagi una història de desig amorós. També és aquest quart participant el que dóna els patrons de personatges tipus: el pare (Uther), el rei (Artur), el cavaller (Lancelot), el conseller savi (Merlí), l'aprenent (Perceval) i també, els dos patrons de dona, la dona bona (Ginebra, prefigurada en Igraine, associada amb l'amor) i la dona dolenta (Morgana, associada amb l'ambició política).

La Morgana de Boorman resulta de la suma d'almenys tres personatges de Malory: Morgana pròpiament dita — Morgan le Fay, que al llibre munta un complot per matar Artur poc després del casament amb Ginebra, però el com-

guionista] key concern was not fidelity to Malory's narrative, which is often meandering, but rather to give the film a classical three-act shape and to place the legend's key ingredients firmly at its center»». plot acaba fallant (Shepherd 2004: 83-97)Morgause _ una altra germana d'Artur, amb qui engendra Mordred (Shepherd 2004: 30) - i la damisella Nínive, de qui Merlí s'enamora al llibre (vegeu el requadre de la p. 40). Amb la construcció d'aquesta Morgana la pellícula aconsegueix crear un antagonista fort — pel caràcter que té i pel fet de ser unitari-, ${ }^{43}$ cosa que ajuda a la unitat d'acció.

Jo no diria tant com que «Women are a largely negative presence in Excalibur» (Coote 2012: 520), perquè no veig que Ginebra sigui duta a representar cap valor negatiu; no té perquè ser negatiu que veiem Ginebra «as enchanting Arthur by giving him a strange cake». Dit això, és cert que les dones hi tenen un paper subordinat al dels homes - i la dona que no el té, Morgana, és la dolenta-: el personatge lgraine-Ginebra o bé és annex a un home - Igraine ho és primer a Cornualla i després a Uther, i Ginebra comença sent-ho al seu pare (Boorman 1981: min. 00:39:33), després ho és a Artur, i finalment a Lancelot—o bé és monja (min. 01:52:28) —annexa a Jesucrist. Aquesta concepció passiva de Ginebra ja és així en Malory. Al llibre, a diferència de la pellícula (min. 01:20:27ss), és Lancelot qui va a Ginebra: Ginebra ha estat segrestada pel cavaller Mellyagaunce, que la té tancada en una cambra; Lancelot va a trobar-la de nit; puja per una escala de mà, arrenca els barrots de ferro de la finestra amb les mans, entra a la cambra de Ginebra i «toke hys plesaunce and hys lykynge»; és cert que Lancelot entra a la cambra perquè ella li demana «that ye myght com in to me» (Shepherd 2004: 632-633). Unes pàgines més endavant, quan considera provada la infidelitat de Ginebra amb Lancelot, Artur decideix fer cremar la reina; Lancelot la rescata a l'últim moment i se l'emporta a Joiosaguarda. Això desencadena una guerra entre Lancelot i Artur que dura pàgines i pàgines, de la sis-cents cinquanta set a la sis-cents setanta-vuit, i que succeeix a banda i banda de la Mànega; en totes aquestes pàgines Ginebra no intervé ni sortint a una finestra per mirar el combat des d'una torre (Shepherd 2004: 657-678).

43 També noten la fusió dels tres personatges de Malory en un antagonista fort Coote (2012: 520) i Hoyle (2012: 121). Lacy (2002: 35) diu que «Boorman is not the first to conflate the figures of Morgan and Morgause». 
No és l'única operació en aquest sentit, sinó que hi ha tot un aparat de guió que treballa perquè la pellícula respecti el principi d'unitat temàtica i espacio-temporal. Les diverses subtrames arrenquen ja des del principi de la pellí́cula, i duren fins al final: el triangle amorós entorn d'Igraine enceta la trama d'amor i prefigura el triangle que pivotarà en Ginebra, triangle, aquest, que no es resoldrà del tot fins al final, quan Artur vagi a trobar Lancelot moribund després de la batalla contra l'exèrcit de Mordred i li demostri que no li té cap rancor - Artur segueix considerant Lancelot com el millor cavaller de la Taula Rodona i «el que és millor en els homes», i Ginebra no ha perdut ni els honors ni l'estatus de reina (min. 02:05:50) —; la trama de Morgana, que es desenvolupa sobretot a la tercera part de la pellícula, ja és present en la primera, quan Morgana sap que el seu pare el duc de Cornualla és mort just abans que Uther arribi a la cambra d'Igraine per engendrar Artur (min. 00:12:57) i té, com he assenyalat, un paper clau de desencadenant del conflicte ja des de la segona part, causant l'acusació de la reina per part de Galvany (min. 01:06:03).

Aquesta voluntat d'unitat fa que els episodis de Malory siguin reordenats i encaixats en una cadena de causes i efectes. A Le Morte Darthur la secció The Noble Tale of the Sankgreal precedeix The Tale of Sir Launcelot and Quene Gwenyvere; a la pellícula és al revés, d'una banda perquè el participant allegòric demana que la primera sigui conseqüència de la segona, i de l'altra perquè el participant argumental vol que tot el que passa vagi en una mateixa direcció. ${ }^{44} \mathrm{Al}$ llibre també hi ha un Combat de la Veritat en què Lancelot defensa la innocència de la reina, però l'acusació sobre Ginebra no té res a veure amb la infidelitat: Lancelot se'n va de Camelot perquè Ginebra li ha dit que no l'estima prou, i ella decideix organitzar un àpat «to shew outwarde that she had as grete joy in all other knyghtes of the Rounde Table as she had in Sir Launcelot» ('per fer veure que gaudia tant amb els altres cavallers com amb Lancelot'); un dels convidats és Galvany, «that he loved well all manner of fruyte» ('a qui agradava molt tota mena de fruita'); sabent això, un altre

44 Marino (2004: 3) també ho explica. dels cavallers, que vol matar Galvany, «empoysonde sertayn appylls» ('va enverinar unes pomes'), amb la mala fortuna que és un cosí del cavaller Mador de la Porte qui en menja primer i mor a l'acte. Mador acusa Ginebra d'haver enverinat les pomes i rep el suport de la majoria de cavallers, i és a partir d'aquesta anècdota que es desenvolupa el Combat entre l'acusador de Ginebra — aquí Mador, a la pellícula Galvany - i Lancelot, que arriba just a temps per defensar la reina (Shepherd 2004: 590-598). Veiem així l'esforç de la pellícula per unificar temàticament els esdeveniments que s'expliquen.

Val la pena notar que l'ordre de les seccions i dels episodis del llibre no és necessari: podria establir-se un altre ordre perquè cada episodi és tancat en si mateix. És clar que caldria modificar alguns detalls de noms i parentius: si Sir Gahallantyne ha mort en la secció anterior no pot sortir en la d'ara, però basta d'intercanviar-li el nom amb Sir Ozanna le Cure Hardy, que mor en aquesta; si Sir Aggravayne no pot ser germà de Galvany, pot ser-ne el cosí, i si no un amic íntim; Galvany podrà voler venjar-ne la mort en tots els casos. El sistema narratiu de Malory és l'acumulació i seqüència d'episodis que, a més, no se succeeixen en un sol fil narratiu sinó en diversos. ${ }^{45}$

Per la raó que sigui — perquè Chrétien de Troyes ja el va escriure combinant aventures de Perceval i de Galvany, o perquè dues novelles diferents van acabar barrejades per error en un sol text-, el Conte du Graal ens ha arribat com una narració per acumulació com la de Malory. En un determinat moment s'oblida de Perceval per explicar l'aventura de Galvany a Tintaguel i a Escavalon, fins que «De monsignor Gauwain se taist | ici li contes à estal. | Si comence de Perceval» ('Del meu senyor Galvany ara calla la història. Aquí comença de Perceval', Potvin 1977: 253). Però després de la trobada de Perceval i el seu oncle ermità, el Conte torna a Galvany: «De Perceval plus longement | ne parole li contes chi; | Ainçois, arons assés oï | de monsigneur Gauwain

45 Vegeu, per exemple, «And now leve we of a whyle of Sir Ector and of Sir Percyvale, and speke we of Sir Launcelot» (Shepherd 2004: 480); «Now woll we leve of thys mater, and speke we off Sir Trystram and of Sir Palomydes that was the Sarazen uncrystynde» (p. 490). 
parler | que rien m'oés de lui conter.» ('De Perceval més llargament no parla el conte a partir d'aquí; abans que em sentiu contar més d'ell, haurem sentit parlar força del meu senyor Galvany', Potvin 1977: 264). Rohmer, per qui el text és al centre de tot, perquè l'únic que vol és fer-lo accessible, manté el primer salt:46 deixa que Perceval se'n vagi i segueix Galvany cap a Tintaguel i Escavalon (min. 01:34:54). Ara bé, com que el seu centre sempre és Perceval, Rohmer no roda les aventures de Galvany posteriors al Divendres Sant de la trobada de Perceval amb l'ermità i, de fet, també elimina la part final de Galvany a Escavalon en què el Conte fa virar els esdeveniments perquè Galvany hagi de partir a la recerca de la llança que sagna. D'aquesta manera, amb les escenes a Tintaguel i Escavalon Rohmer manté una marca dels canvis de trama del text original; al mateix temps, aquest parèntesi és necessari si quan la narració retorni a Perceval («le conte se tait de Messire Gauvain et revient à Perceval») han d'haver passat «cinq fois [.. . ] avril et mai, | ce sont cinq ans tout en entier» ('cinc vegades abril i maig, és a dir cinc anys sencers', min. 01:57:00).

El final de Perceval le Gallois és ambigu. D'una banda, Rohmer fa un esforç perquè l'aventura de Perceval no quedi inacabada: tant l'escena amb l'ermità com sobretot l'escena final de la Passió busquen completar l'aprenentatge que ha de fer Perceval i alhora tancar la trama oberta amb la processó de la llança i el Graal al castell del Rei Pescador, les expectatives de la qual s'han revifat quan Perceval ha promès que trobarà els dos objectes per esmenar el seu error de no haver preguntat què eren (min. 01:34:27). Així, l'ermità respon la pregunta sobre el Graal: el contingut del Graal és pel pare del Rei Pescador, germà de la mare de Perceval i, doncs, oncle seu com l'ermità mateix (min. 02:01:52); i el pla detall conclusiu de l'escena de la Passió explica que la sang que regalima de la punta de la llança que sagna és la de Jesucrist (min. 02:11:48). Contra aquest esforç per tancar la narració queda oberta l'aventura

46 Vegeu Coote (2012: 515): «Instead of a closely woven tripartite structure such as that of Bresson or Boorman, Rohmer adopts the episodic structure of his source text, retaining almost all of Chrétien's episodes in their original order». de Galvany i, sobretot, s'afegeix un pla de Perceval que surt de l'enquadrament a buscar noves aventures: «Le chevalier sans nul arrêt | va chevauchant par la forêt...» ('El cavaller sense pausa cavalca pel bosc', min. 02:11:59).

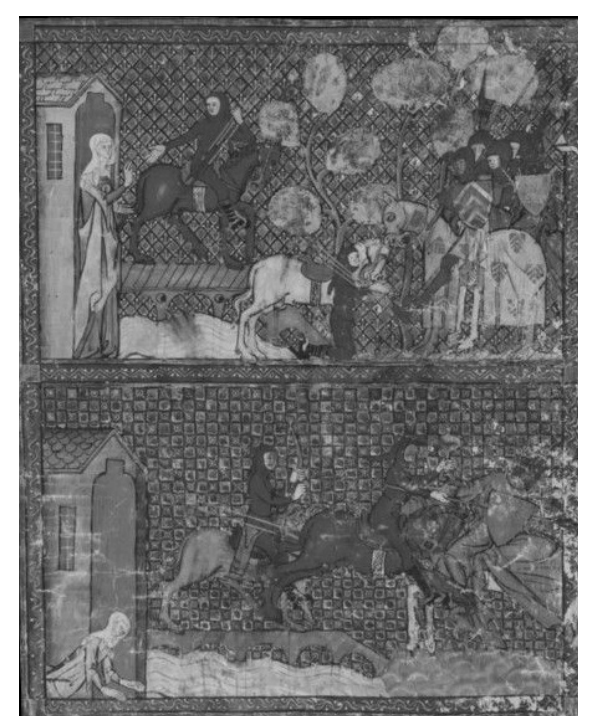

Perceval surt a passejar; Perceval troba els cavallers; Perceval marxa de casa seva; Perceval mata el Cavaller Vermell (París, BnF, fr. 12577, f. 1, 1330?) 


\section{Bibliografia}

BOORMAN, John (1981): Excalibur.

Boorman, John 1986: Money into Light. The Emerald Forest: A Diary, Londres: Faber and Faber.

Burch, Noël, 2007: La lucarne de l'infıni: Naissance du langage cinématographique, París: L'Harmattan.

Chal-Elsholz, Raeleen \& Jean-Marc ELSHOLZ 2015: «John Boorman's Excalibur and the Irrigating Light of the Grail», The Holy Grail on Film: Essays on the Cinematic Quest, ed. Kevin J. Harty, Jefferson: McFarland, 98-111.

COOTE, Lesley, 2012: «The Art of Arthurian Cinema», A Companion to Arthurian Literature, ed. Helen Fulton, Oxford: Blackwell, 511-524.

DAVIDSON, Roberta, 2007: «The Reel Arthur: Politics and Truth Claims in Camelot, Excalibur, and King Arthur», Arthuriana, 17.2, 62-84.

Donovan, Richard B., 1958: The Liturgical Drama in Medieval Spain, Toronto: Pontifical Institute of Mediaeval Studies.

Douchet, Jean (1978): En répétant Perceval.

GRIMBERT, Joan Tasker \& Norris J. LACY, 2009: «Arthur in Modern French Fiction and Film». The Arthur of the French, ed. Glyn S. Burgess i Karen Pratt, Caerdydd: University of Wales Press, 546-570.

Hoyle, Brian, 2012: The Cinema of John Boorman, Toronto: Scarecrow.

KaWA-TOPOR, Xavier, 2011: Conferència sobre Perceval le Gallois d'Éric Rohmer al Forum des Images. http://www.dailymotion.com/ video/xmrwma_cours-de-cinemaperceval-le-gallois-d-eric-rohmeranalyse-par-xavier-kawa-topor_ shortfilms [darrera consulta: 15 de juliol de 2016].
KeLLY, Douglas, 2009: «Chrétien de Troyes», The Arthur of the French, ed. Glyn S. Burgess i Karen Pratt, Caerdydd: University of Wales Press, 135-185.

KeNNEDY, Harlan, 1981: «Excalibur: John Boorman - In interview»», http:// americancinemapapers.homestead. com/files/EXCALIBUR.htm [darrera consulta: 15 de juliol de 2016].

LACY, Norris J., 2002: «Mythopoeia in Excalibur», Cinema Arthuriana: Twenty Essays, ed. Kevin J. Harty, Jefferson: McFarland, 34-43.

LEMONS, Stephen, 2001: «John Boorman», http://www.salon. com/2001/o4/o2/boorman/ [darrera consulta: 15 de juliol de 2016].

Magny, Joël \& Dominique Rabourdin 1979: «Entretien avec Éric Rohmer», Cinéma, 242 (febrer), 11-19.

MARINO, John B., 2004: The Grail Legend in Modern Literature, Woodbridge: Boydell \& Brewer.

McFARLANe, Brian, 1996: Novel to Film: An Introduction to the Theory of Adaptation, Oxford: Clarendon.

Pickens, Rupert T., 2005: «Le Conte du Graal: Chrétien's Unfinished Last Romance», A Companion to Chrétien de Troyes, ed. Norris J. Lacy i Joan Tasker Grimbert, Woodbridge: Boydell \& Brewer.

Potvin, Ch, 1977: Troyes, Chréstien de Troyes, Perceval le Gallois ou Le Conte du Graal, 2 vols, Ginebra: Slatkine.

Putter, Ad, 2009: «The Twelfth-Century Arthur», The Cambridge Companion to the Arthurian Legend, ed. Elizabeth Archibald i Ad Putter, Cambridge: Cambridge University Press, 36-52.

RIDER, Jeff, Richard HuLL, Christopher SMITH, Michael Carnes, Sasha FoPPIANO \& Annie HESSLEIN, 2002: «The Arthurian Legend in French
Cinema: Robert Bresson's Lancelot du Lac and Eric Rohmer's Perceval le Gallois», Cinema Arthuriana: Twenty Essays, ed. Kevin J. Harty, Jefferson: McFarland, 149-162.

Riquer, Martí de, 1995: Chrétien de Troyes. El conte del graal, Barcelona: Quaderns Crema.

Rohmer, Éric (1978): Perceval le Gallois.

Rouse, Robert Allen \& Cory James RusHTON, 2009: «Arthurian Geography», The Cambridge Companion to the Arthurian Legend, ed. Elizabeth Archibald i Ad Putter, Cambridge: Cambridge University Press, 218-234

SHePHeRd, Stephen H.A. (ed.), 2004: Sir Thomas Malory, Le Morte Darthur, Nova York - Londres: W.W. Norton.

ODE = Oxford Dictionary of English, ed. Catherine Soanes, Angus Stevenson et al., Oxford: Oxford University Press, $2006^{2}$.

TOURNIER, Christine, 1979: «Perceval le Gallois: Découpage après montage définitif et dialogue en extenso»», Avant-scène Cinéma, 221 (febrer), 9-64.

TRÀILER DE PERCEVAl: https://www. youtube.com/watch? $v=h n f 2-$ YjBLRA [darrera consulta: sis de desembre del 2014].

TRÀILER D'EXCALIBUR: https://wWw. youtube.com/watch? $\vee=$ joiyhX $\mathrm{r}_{\text {_ }}$ wqw [darrera consulta: sis de desembre del 2014].

WHITAKer, Muriel, 2002: «Fire, Water, Rock: Elements of Setting in John Boorman's Excalibur and Steve Barron's Merlin», Cinema Arthuriana: Twenty Essays, ed. Kevin J. Harty, Jefferson: McFarland, 44-53.

WINDEATT, Barry, 2009: «The FifteenthCentury Arthur», The Cambridge Companion to the Arthurian Legend, ed. Elizabeth Archibald i Ad Putter Cambridge: Cambridge UP, 84-102. 